\title{
Novas formas de operar o real? Algumas implicações estéticas e éticas do toque sobre imagens ${ }^{1}$
}

New Ways of operating the real? Some Aesthetic and Ethical Implications of Touching Images

\author{
Eli Borges Junior \\ Universidade de São Paulo \\ ridolfi.eli@gmail.com
}

Resumo: Dentre as tantas transformações físicas e culturais que advêm das novas tecnologias e do uso de seus gadgets, há uma que mais nos chama a atenção e talvez exija uma forma de análise para além dos limites da tecnofilia ou da tecnofobia: a questão dos gestos. É nesse sentido que escolhemos um determinado gesto, a partir do qual se dará nossa discussão: o «touch». Ao contrário de qualquer imagem tradicional, a imagem digital (desde as telas de celulares até os recursos de Realidade Virtual e Realidade Aumentada) é uma superfície que pode e deve ser «tocada». A partir do toque, a dinâmica e a diferença entre o distante e o próximo parecem operar com uma vivacidade incomparável em

\footnotetext{
1 Versão revisada e aprimorada de comunicação apresentada durante o « II Congreso Internacional Comunicación y Filosofía realizado em Priego de Córdoba, Espanha, em 2019. Este artigo é decorrente de uma investigação de doutorado. Trata-se, aqui, de uma versão adaptada do texto da tese (ver Borges Junior, 2020).
} 
comparação a nossos outros sentidos. Embora não discutamos aqui especificamente sobre os sentidos humanos e seus limites, é interessante notar que parece haver, grosso modo, uma transformação na própria configuração pela qual os sentidos participariam desse novo modo de acessar uma imagem. Nessa linha, pretendemos nos basear principalmente em obras como a de Vilém Flusser e sua filosofia sobre os gestos, bem como nas contribuições de Giorgio Agamben e Erwin Straus. Tudo isso visa problematizar as seguintes questões: como a possibilidade de «tocar» altera nossa relação com a imagem? Em que medida isso transforma nossa experiência e contribui para a delimitação de nossa percepção do «real»? E, finalmente, quais são as implicações éticas e mesmo políticas que esse novo gesto acarretaria?

Palavras-chave: imagem, gesto, ética e estética, digital, touch screen.

Abstract $^{2}$ : Among the many physical and cultural transformations that come from new technologies and the use of their gadgets, there is one that most arouses our attention and perhaps demands a way to analyse beyond the limits of technophilia or technophobia: the question of gestures. It is in this sense that we choose a particular gesture, from which our discussion will take place: the «touch». Unlike any traditional image, the digital image (from mobile phone screens to Virtual Reality and Augmented Reality features) is a surface that can and should be «touched». From the touch, the dynamics and the difference between the distant and the near seem to operate with unparalleled liveliness compared to our other senses. Although

2 Abstract publicado no livro de resumos do «II Congreso Internacional Comunicación y Filosofía», Priego de Córdoba, Espanha (2019). 
we do not discuss here specifically about the human senses and their limits, it is interesting to note that there seems to be, roughly, a transformation in the very configuration by which the senses would participate in this new mode of accessing an image. From this, we intend to be based mainly on works such as Vilém Flusser's and his philosophy on gestures, as well as the contributions of Giorgio Agamben and Erwin Straus. All this aims to problematize the following questions: how does the possibility of «touch» change our relationship with the image? To what extent does it transform our experience and contribute to the delimitation of our perception of the «real»? And finally, what are the ethical and even political implications that this new gesture would entail?

Keywords: image, gesture, ethics and aesthetics, digital, touch screen.

Fecha de recepción: $27 / 7 / 2020$

Fecha de aceptación: 17/2/2021 

Introdução: os gestos como sintomas de uma época

Em uma de suas mais recentes obras, Agamben é enfático ao sentenciar que «a política e a ética do Ocidente não se libertarão das aporias que acabaram por lhes tornar impraticáveis se o primado do conceito de ação $[. .$.$] não for posto radicalmente$ em questão» ${ }^{3}$. O tema da ação é justamente o ponto problemático do arco entre a estética e a ética e é aquilo que nos permite reconhecer e explorar a porosidade dessa relação entre ambas. Disso então resulta uma pergunta: o que certas transformações no campo tradicional da ação têm propriamente a ver com os modos pelos quais hoje operam as imagens? Ou ainda: em que medida o advento dessas imagens, bem como de seus dispositivos tecnológicos, estaria relacionado a uma transformação da ética e da política?

Se podemos apontar o problema do atual e embaraçoso estatuto da verdade como um sintoma candente da generalização das imagens ${ }^{4}$, outro fenômeno sintomático —e que não deixa de guardar proximidade com o primeiro-é aquilo que poderíamos descrever como uma transformação da gestualidade. Desdobre-

3 Tradução nossa. No original: «La politique et l'éthique de l’Occident ne se libéreront pas des apories qui ont fini par les rendre impraticables si le primat du concept d'action [...] n'est pas mis radicalement en question» (Agamben, 2018: 93).

$4 \mathrm{O}$ que seria tratado a partir de perspectivas diversas, seja em Muniz Sodré, por meio de uma «estetização generalizada pela ação das mídias» (Sodré, 2014: 145), seja mesmo por aquilo que, em um espectro ainda mais amplo, Gilles Lipovetsky e Jean Serroy descrevem como uma «estetização do mundo» (ver Lipovetsky, Serroy, 2013). Não seria, contudo, hiperbólico reler esse processo como o ponto de hipertrofia de algo já, em certa medida, anunciado, muitas décadas antes, por Walter Benjamin ao refletir sobre a questão da imagem na era da reprodutibilidade técnica (ver Benjamin, 2014). 
mos cuidadosamente essa hipótese, inicialmente, por aquilo que compreendemos por «gesto» ${ }^{5}$.

Gesto de revolta, gesto de carinho, gesto de apreensão, gesto de terror. O que todos têm em comum? Seriam eles meios para que determinados fins fossem alcançados? Ou, ao contrário, seriam eles consequências de determinados estados de espírito, «efeitos» visíveis que esboçamos como resultado direto de determinados afetos? Pois Agamben nos diria que nem exatamente uma coisa, nem outra: o gesto é algo extremamente singular porque escapa a essas duas possibilidades.

Agamben dirá que o gesto é uma «medialidade pura e sem fim que se comunica aos homens» (Agamben, 2008: 13). Essa é, pois, a singularidade do gesto para a qual gostaríamos de chamar a atenção. $\mathrm{O}$ gesto não pode ser concebido dentro de uma relação causa-consequência, como elemento precipitador de algo que lhe sucede como efeito: o gesto não é propriamente «necessário» para que esse algo ocorra, mas sua presença é capaz de associar, a esse algo, a singularidade de sua força. É como se esse «resultado» ganhasse um brilho especial com o gesto. Ora, o grito ou o braço ao alto no protesto não têm uma finalidade específica ${ }^{6}$. Basta imaginarmos que, em si mesmos, não possuem qualquer "poder de fogo»: o grito ou o braço ao alto jamais poderiam nos levar a alcançar a vitória em uma batalha. Não por si mesmos. Do mesmo modo, poderíamos pensar nos movimentos do mimo ou na dança ${ }^{7}$ : todos esses exemplos não produzem

5 A reflexão sobre esse tema já seria por nós principiada no artigo Os novos gestos da política: sobre cidadania e formas estéticas de resistência na era digital (Borges Junior, 2018), publicado na revista Lumina (UFJF). Na ocasião, trabalhamos sobre a definição de gesto que Agamben nos oferece em seu breve ensaio Note sul gesto, o qual compõe o volume Meži senza fine (Agamben, 1996). Aproveitamos aqui para complementar tal definição a partir do que Agamben escreveria em seu recente livro Karman: court traité sur l'action, la faute et le geste (Agamben, 2018).

6 Ver Borges Junior, 2018.

7 Exemplos de Agamben (1996: 51-52). 
nada além de expressão, pois «o gesto expõe e contempla a sensação na sensação, o pensamento no pensamento, a arte na arte, a palavra na palavra, a ação na ação» (Agamben, 2018: 127).

Essa condição de pura medialidade ${ }^{8}$, que nada visa como fim, recebe em Flusser um exemplo cristalino ${ }^{9}$. Poderíamos compreender o gesto como o ato de fumar um cachimbo. Há aí uma dimensão racionalizável, ou seja, que poderia explicar tal ato como a inalação de fumo, ou mesmo como a satisfação de uma necessidade fisiológica, no caso de um vício. Mas «fumar um cachimbo» enquanto gesto é tudo menos essa dimensão racional. Sua gestualidade reside justamente naquilo que escapa a essa última. Embora com um vocabulário distinto do de Agamben, é possível dizer que aqui Flusser sugere praticamente a mesma ideia:

A finalidade do gesto não é inspirar fumo, que isto não passa de pretexto do gesto, e que a sua verdadeira finalidade é precisamente fazer os movimentos complexos do gesto. Em outros termos, se trata de gesto que é sua própria finalidade. Em suma, se trata de um rito. [...] No rito, a práxis é antiprática: o gesto não visa meta externa, e a inalação de fumo é apenas pretexto. [...] O fumante afirma que fuma para inalar fumo, e quando diz, o crê, e o fumo é «bom». Mas, a despeito da sua «boa fé», está enganado. Fuma para fazer o gesto. (Flusser, 2014: 32-33, 35)

Por isso, o gesto é simplesmente «a exibição de uma medialidade, o tornar visivel um meio como tah) (Agamben, 2008: 13) ${ }^{10}$, um fumar que não depende paradoxalmente daquilo que se anuncia como seu objetivo prático: inalar o fumo. Com a dimensão do gesto,

8 Ver Agamben, 2018: 127.

9 Em sua última obra Gesten, coincidentemente publicada um ano antes das Note sul gesto de Agamben.

10 Itálico do autor. 
percebemos como boa parte de nossas ações podem nos ser muito mais compreensíveis do que aquilo que os limites entre meios e fins nos ofereciam. Percebemos, assim, que, embora acreditemos explicar muitos de nossos atos a partir de causas —em um primeiro exame- «simples», «fáceis» de identificar, elas não correspondem de fato ao que nos move em sua direção. Nos gestos, agimos simplesmente para fazê-los — aqui lembramos a etimologia de Flusser: «gesta» $=$ «feitos» (Flusser, 2014: 19)-. Sua força se resume, assim, ao simples fato de existirem e de poderem, de algum modo, tornar-se visíveis. O gesto é o grito que persiste, ainda que consciente da inocuidade da resistência. O gesto é a «comunicação de uma comunicabilidade» (Agamben, 2008: 13): a expressão não apenas de um grito em si, mas, de um «posso ainda gritar».

E é por isso que, de um determinado modo, todo gesto contém em si mesmo alguma incompletude. Mas sua incompletude tem a incrível capacidade de converter-se no mais cristalino dos efeitos: o grito de resistência, a derrubada da estátua do antigo líder político, o braço que se ergue sobre a cabeça antes do tiro de misericórdia. Sua força está na visibilidade dessa sua incompletude. Um gesto nada produz, nem age como fim, não visa nada além de si mesmo: o que um gesto faz é assumir e suportar ${ }^{11}$. Todo gesto é, portanto, uma forma de resistência em relação à ordinariedade do mundo ${ }^{12}$.

Indizível e insubstituível, mas com uma «comunicabilidade» profunda e algo que só ele mesmo pode expressar: não pode ser repetido senão em sua forma material; sua força, sua energia perturbadora, no entanto, estão além dela. Sem necessidade de tradução, eis o gesto: elemento comunicativamente universal.

11 Ver Agamben, 2008: 12.

12 Ver Borges Junior, 2018: 87.

Borges Junior, Eli (2021). «Novas formas de operar o real? Algumas implicações estéticas e éticas do toque sobre imagens». Monograma. Revista Iberoamericana de Cultura y Pensamiento, n. ${ }^{\circ}$ 8, pp. 161-180. doi: 10.36008/monograma.2021.08.2054. http: revistamonograma.com. ISSN: 2603-5839. 
Há na conversa, na fala em público, gestos que são anteriores ao seu próprio conteúdo semântico: há ali uma dimensão primeira que é aquilo que nos torna visíveis, aquela pela qual podemos «aparecer» para o outro. É por isso que os gestos são a essência da política, o seu meio de expressão primeiro e último, ou, como escreve Agamben, «a política é a esfera da integral gestualidade dos seres humanos» (Agamben, 2018: 221). É por seus gestos que o homem «aparece» enquanto ser inscrito em um determinado meio: «o gesto faz aparecer o ser-num-meio do homem e, deste modo, abre para ele a dimensão ética» (Agamben, 2008: 13). Daqui, uma lição importante: é pelos gestos que nos afirmamos política e eticamente. É por eles que de fato nos comunicamos a fim de construir um «comum». É por eles, e somente por meio deles, que nossas ações aparecem ao outro e ao mundo.

O gesto é, assim, o que nos permite ir do domínio do eu para o domínio do nós. Há sempre no gesto um jogo entre nós e o mundo. E é nesse sentido que, como proclamaria Flusser, o «gesto é um movimento no qual se articula uma liberdade, a fim de se revelar ou de se velar para o outro» (Flusser, 2014: 16-17). Os gestos são nosso primeiro e nosso último reduto da condição de seres livres: é por eles que anunciamos que nascemos ou que deixamos a vida. Quando qualquer linguagem mais sofisticada nos falta, é o chorar nossa primeira e ainda única possibilidade de exercê-la. Chorar é um gesto, ali o único recurso que possuímos a fim de anunciarmos, para falar com Agamben, nosso «ser-num-meio». Assim como o grito de dor: é esse gesto a última fenda pela qual a liberdade do acossado ainda se faz perceptível (ele sabe que o grito não o livrará da dor iminente); é por esse gesto que o condenado expressa o último fio de resistência à sentença da própria morte. O que resta é apenas esse gesto. 
Mas, como bem ressalva Flusser, «nem todo movimento do corpo humano é gesto» (Flusser, 2014: 17). O erguer do punho fechado para cima pode ser tanto a expressão de revolta como de um espreguiçar ${ }^{13}$. Ambos são movimentos fenomenologicamente semelhantes, porém o que o filósofo nos ajuda a compreender é que o segundo não poderia ser concebido como um gesto: trata-se de um movimento que poderia ser «satisfatoriamente explicado» (Flusser, 2014: 17); ele «não articula uma liberdade» e isso quer dizer que poderia muito bem ser compreendido, por exemplo, como uma reação fisiológica de nosso corpo (a qual inclusive podemos ver em outros animais). O primeiro movimento, no entanto, é ele, sim, um «gesto»: o erguer do punho durante o levante «articula uma liberdade» e por esse movimento se é capaz de «revelar ou de se velar para o outro». O gesto de revolta é a expressão de um assentimento, por mais «cultural» que isso seja: «O que articula todo gesto é a convicção subjetiva de ser livre» (Flusser, 2014: 34). Poder-se-ia não o fazer, já que, no limite, não está associado a nenhum fim que não seja si mesmo (assim como o ato de fumar cachimbo). O gesto de revolta não tem qualquer capacidade de fazer fugir à opressão, não estritamente enquanto gesto. $\mathrm{O}$ gesto é, nesse sentido, um puro modo de se colocar $^{14}$, de se colocar diante de um outro a partir de um modo próprio (porque assentido, ainda que tal assentimento brote dos mais profundos e inacessíveis recônditos do espírito), que justamente por isso, serve como traço mesmo de identificação. Nem todo movimento é gesto (ao modo de Flusser), mas todo gesto é político e ético ${ }^{15}$. É o que as palavras de Didi-Huberman fazem transluzir na descrição do exemplo do gesto do levante:

\footnotetext{
13 Aqui o exemplo é nosso.

14 A sua «medialidade pura» (evocando Agamben) assegura-lhe a liberdade.

15 Assim como nos complementa Flusser: «O que distingue gestos dos demais movimentos não é nem a sua intensidade nem a sua eficiência, mas o fato de terem sido deliberados. Gestos são fenômenos do nível ético da realidade: são motivados, 'livres’» (Flusser, 2014: 112-113).
} 
Levantar-se é um gesto. Antes mesmo de começar e levar adiante uma «ação» voluntária e compartilhada, o levantar se faz por um simples gesto que, de repente, vem revirar a prostração que até então nos mantinha submissos (por covardia, cinismo ou desespero). Levantar-se é jogar longe o fardo que pesava sobre nossos ombros e entravava o movimento [...] No gesto do levante, cada corpo protesta por meio de todos os seus membros, cada boca se abre e exclama o não da recusa e o sim do desejo. (Didi-Huberman, 2017: 117) ${ }^{16}$

Sem os gestos, não teríamos como «aparecer» no mundo e assim nos colocarmos «para» e «com» ele. «A existência se manifesta por gestos», escreveria Flusser; inelutavelmente «o homem está no mundo na forma dos seus gestos» (Flusser, 2014: 36). Seu exemplo do gesto da escrita é cristalino: «ao apertar as teclas de minha máquina, toda a minha existência se concentra sobre as pontas dos meus dedos, estou no mundo por intermédio das pontas dos meus dedos» (Flusser, 2008: 35). Os gestos têm, assim, um papel impreterível e não seria mesmo por acaso que o filósofo tcheco defenderia, como campo de estudos fundamental, uma «teoria geral dos gestos», antecâmara de disciplinas como a sociologia, a psicanálise ou a comunicação.

Mas aonde gostaríamos de chegar propriamente com todas essas definições? Ora, elas nos ajudam a perceber a singularidade do gesto e seu papel central no mundo da vida: como gênero próprio do agir, sob a condição comunicativa indizível e paradoxal de «medialidade pura» ${ }^{17}$; ou como constatação fulcral: o gesto é, por excelência, ético e político. Ele está inalienavelmente presente na constituição de um «comum», ainda que, em certas ocasiões, não aja diretamente no campo da política propriamente

16 Leiamos aqui «levantar-se» como «sublevar-se».

17 Ver Agamben, 2018: 127. 
dita. Pois se há uma esfera pela qual tudo deve atravessar e se há uma esfera em que tudo se converte a fim de que adquira um caráter social, essa esfera é a dos gestos.

Os gestos e suas características não se exprimiriam, assim, como «sintomas» de uma época? Sintomas como traços daquilo que podemos dela apreender, mas sem qualquer ligação necessária com ela? É o que Flusser nos deixa ver quando defende a observação dos gestos como uma espécie de método para descrevermos nossa condição contemporânea: «se pudermos de fato observar mutações em [um] gesto, estaríamos observando uma manifestação de modificação profunda na nossa cultura, portanto, na maneira pela qual existimos» (Flusser, 2014: 44).

Mas, da mesma maneira que, pelos gestos, podemos identificar transformações de nossa existência, uma alteração dos gestos também não poderia, a sua maneira, alterar nosso próprio modo de existir no mundo? O que implicaria, assim, o declínio ou a ascensão de uma gestualidade específica?

\section{O touch como gesto próprio da era digital}

É visando essa noção de gesto como sintoma de nossa existência que Flusser escreve: «o gesto pelo qual o vídeo está sendo manipulado é parcialmente modificação de gestos tradicionais, e parcialmente gesto de tipo novo. Observá-lo seria, pois, [...] método para "ler" a crise existencial pela qual estamos passando" (Flusser, 2014: 73). Estendamos o significado disso para além do vídeo, compreendendo sobretudo as redes digitais, e teremos assim uma descrição interessante do que aqui aventamos. Qual seria então, nesse contexto conectado, o seu «gesto de tipo novo»? Em que os gestos inaugurados pelo contexto das redes se diferenciariam dos gestos tradicionais? 
A explosão das imagens e de seus dispositivos digitais abriu espaço para o advento de um gesto muito particular: trata-se do touch, o gesto a partir do qual tocamos a imagem. Atentemo-nos, aliás, à interessantíssima amplitude semântica desse termo.

«Touch» pode significar - como verbo- o «tocar pelo tato», o «entrar em contato», o «apalpan», o «pegan», o «alcançar» e também o «esbarrar» (o que nos traz um certo sentido de surpresa, de não saber o que de fato se encontrará). O toque envolve sempre o convite a um desconhecido: o tocar é a abertura de um circuito contingente que se fecha apenas quando o toque é efetivado. Há, portanto, no toque sempre um nível de mistério, por mais que o objeto tocado seja familiar, já que nada pode substituir a sensação mesma do toque: nem a mais potente imaginação poderia trazer à nossa pele a sensação pura e completa do quebrar das ondas do mar em nossas costas. Só o toque possui essa propriedade. Esse nível de mistério fica mais interessante ao visitarmos os outros significados do verbo: touch é também «afetar», é «tocar o coração», é «sensibilizar», é «comover». E aqui o tato, o mais «material» dos sentidos, converge com a abstração extrema dos afetos, ambos em uma mesma palavra: touch como uma porta de entrada, concreta, do sentir. Touch como uma reunião entre o possível da materialidade com o impossível do abstrato: reunião que descreve um elemento fundamental da magia. Não é mesmo bastante sintomático que Flusser, mutatis mutandis, tenha atribuído ao «tatear» um aspecto «mágico» ${ }^{18}$ ?

A imagem digital, distintamente de qualquer imagem que aqui poderíamos chamar de «tradicional», é uma imagem que pode e deve ser «tocada». A possibilidade do touch muda por completo nossa relação com a imagem. O tocar tem uma efetividade

18 Ver Flusser, 2008. Diria Flusser, por exemplo: «enquanto permito às pontas de meus dedos tatearem o teclado da minha máquina de escrever, estou fazendo magia [...]» (Flusser, 2008: 32). 
ímpar no exercício de acesso a nosso «mundo real» ou àquilo que percebemos como imediatamente próximo a nós. Isso nos faz recordar Erwin Straus em sua defesa do tato como sentido que melhor transmite «O conteúdo comunicativo do próximo» ${ }^{19}$. A partir do tato, a dinâmica e a diferença distante/próximo parecem operar com uma vivacidade inigualável quando comparada aos nossos outros sentidos (e isso não tem a ver necessariamente com as possibilidades ou impossibilidades que o tato teria de «conhecer»). Se a audição e a visão (os «sentidos de distância» ${ }^{20}$ ) são as grandes privilegiadas no formato tradicional de fruição das imagens ${ }^{21}$ — poderíamos associar aqui a visão e a audição como os sentidos da razão-, talvez não fosse despropositado postular que, no contexto digital, o tato, um dos «sentidos de proximidade», ganha um papel nunca antes experimentado na relação com a imagem.

Com o touch, nossa relação com a imagem se transforma, mas em que propriamente? Pois, pela primeira vez na história, profanamos a imagem com o nosso toque sobre ela. Ora, não parece haver algo de proibido, de inacessível, ou quase mesmo algo de «sagrado» na tela da televisão e no telão do cinema? Há como se imaginar heresia maior do que lançar a mão sobre a grande tela de projeção do filme? Alguém já se atreveu? Não nos vem quase que um sentimento de «pecado» ao presenciarmos algum «herege» que ousa estraçalhar seu monitor no chão ou meter-lhe a marreta como na postura dos iconoclastas medievais? A imagem, nesses contextos, é algo intocado e intocável.

19 Segundo Straus, «[le sens tactile] transmet le contenu communicatif de l'approche mieux que toute autre modalité» (Straus, 2000: 453).

20 Como associa Straus, evocando o que chama de classificação «habitual» dos sentidos (Straus, 2000: 452).

21 Pensemos, por exemplo, na arquitetura teatral clássica e em sua preocupação com a disposição dos espectadores de maneira que possam «ver» e «ouvir» o espetáculo com a maior acuidade possível. Tocá-lo, jamais. 
Rompendo com essa condição, o touch é, assim, uma espécie de passaporte para uma outra modalidade de acesso à imagem. Se o tato cresce em importância já com a explosão dos botões e das teclas ${ }^{22}$, o touch será a explosão definitiva desse jogo entre concretude e abstração. Para que esse seja efetivamente operado, é necessário que, na própria relação com a imagem, mantenhamos um vínculo com o concreto, ou seja, o toque sobre ela. É então que se rompe definitivamente aquela separação estrita entre a imagem e nós, desintegrando as convencionais classificações entre «espectadon» e «imagem», «observadon» e «observado», assim como em um limite mais profundo, entre «sujeito» e «objeto». Esse rompimento se dá, portanto, com a possibilidade de tocar a imagem, de acessá-la a ponto de ingressarmos nela, habitando-a e, assim, fazendo dela nosso próprio «mundo real». É assim que, com as experiências de realidade virtual e realidade aumentada, ao invés de inscrevermos a imagem como parte de nosso mundo, somos inscritos como parte dela, convertidos então em zeros e uns, passando a fazer parte de seu mundo próprio. Nesse tipo de fruição, não mais «vemos e ouvimos» a imagem como seus «espectadores», mas — a partir das operações dos dispositivos que interagem com os nossos próprios movimentossomos, sim, «vistos e olhados» por ela.

A questão do touch está indissociavelmente ligada à própria natureza da ação nesse contexto digital. Não seria o touch um modo de exorcizar aquela necessidade (mesmo histórica) de algum contato material com o mundo para que, com isso, possamos atestar nossa capacidade de transformá-lo? O botão, a

$22 \mathrm{E}$ isso seria muito bem tratado por Flusser ao descrever a «imagem técnica» (Flusser, 2008: 31-38). Poderíamos dizer que o botão e a tecla são precursores do touch, uma vez que consistem já em uma forma de toque — porém indireta— sobre a imagem. É por isso que, em uma perspectiva mais ampla, ao abordarmos a questão do touch, acabamos por contemplar também o botão e a tecla. 
tecla e o touch nos deixam órfãos de gestos. Em uma espécie de efeito estandardizante, agregam em si a miríade de gestos que antes, juntamente com as sensações a eles associadas, operavam como um atestado de nossas ações no mundo (como proclama Flusser, não é por eles que de fato existimos?). Sem esses gestos, o toque sobre a imagem seria, então, um modo de demonstrar, a partir do corpo (e mesmo pelo movimento dele), alguma forma de atuação no mundo, alguma intervenção sobre ele, algo que, de certo modo, ofereça-nos ao menos a «sensação» de nele estar modificando alguma coisa?

Se, de fato, transformamos ou não, é algo que merece uma discussão futura aprofundada. Por ora, é fato que o touch não nos deixa de oferecer essa sensação de poder transformar algo, ao menos a própria imagem. Por milênios intacta, imaculada, inviolável, modificá-la era então impossível, sob pena mesmo de aniquilá-la (não é justamente isso que tonifica o embate benjaminiano entre «aura» e «reprodutibilidade técnica»?). Restava, então, a capacidade imaginativa como único recurso capaz de «distorcê-la» em alguma medida, claro que nunca no nível do concreto, mas apenas do abstrato; afinal, a tela e a escultura são permanentes e o que está impresso sobre o filme ou a película será sempre o mesmo fotograma; modificá-los é função exclusiva de seu único demiurgo: o fotógrafo, o diretor ou o artista.

Em suma, o touch converte-se na possibilidade de sentir a imagem mesma pelo movimento do corpo. Em nossos dispositivos, não tocamos propriamente a onda do mar, mas tocamos algo (ainda que o ar) como se o fosse. Isso porque não é o «algo» tocado, por meio de sua materialidade, que concede a nós a percepção de que existe, mas sim nosso toque enquanto puro gesto. O fato de «tocar», ainda que uma imagem, já contribui para essa sensação (que não é a mesma do toque na água do mar, que fique 
claro): há uma energia própria no «tocar». Mas o tocar aqui é o tocar uma imagem e não o tocar a materialidade da onda. E por isso a natureza desse gesto é diversa.

Com o touch, somos liberados para o contato físico com a imagem, satisfazendo o desejo de profaná-la (o «don't touch» dos museus não inflama ainda mais nosso desejo do toque?). Podemos então tocá-la e, mais ainda, modificá-la a nosso bel-prazer: podemos fazer dela uma expressão para nossos mais reservados desejos (uma fotografia romântica, uma videoconferência reservada) ou, por meio dela, experimentar possibilidades do futuro $^{23}$ : pensemos na evolução desde os primeiros programas de edição de imagens até os aplicativos que hoje, com recursos de Inteligência Artificial (ou seja, dados e algoritmos altamente complexos), contam até mesmo com a incrível capacidade de oferecer-nos outras aparências, outros estilos ou mesmo as rugas e as linhas de expressão de toda uma vida ${ }^{24}$. Tudo a partir de um breve movimento do corpo: o arrastar dos dedos ou, no limite, um deslocar de braços e pernas.

Mas, se o touch, como algo mágico (mais ainda do que o botão ou a tecla), dá-nos acesso nas pontas dos dedos a essa miríade de novas possibilidades, o que são feitos dos gestos que antes envolviam todas essas tarefas? Em que se converte toda aquela gestualidade anterior - gestos do esperar, gestos do descobrir, gestos do aprender, gestos do resistir_-, ou ainda, o que seria daquela sua força própria, daquela sua energia, ou mesmo daquela sua vocação à liberdade? Pois essas são questões para passos futuros de nossa investigação.

23 De fixidez, permanência, a imagem converte-se em mobilidade, imprevisibilidade, acontecimentalidade (em uma dinâmica que se aproxima muito daquela do mundo da vida).

24 Por exemplo, nos aplicativos móveis e seus recursos de Inteligência Artificial capazes de nos fornecer estimativas sobre nossa aparência após uma mudança de visual, sobre como seremos ao envelhecer ou mesmo sobre como serão os rostos de nossos filhos. 
Agradecimentos

Texto decorrente de bolsas de doutorado: processo n. ${ }^{\circ}$ 2016/03588-7 e processo n. ${ }^{\circ}$ 2018/06565-3, Fundação de Amparo à Pesquisa do Estado de São Paulo (FAPESP). As opiniões, hipóteses e conclusões ou recomendações expressas neste material são de responsabilidade do autor e não necessariamente refletem a visão da FAPESP. 


\section{REFERÊNCIAS BIBLIOGRÁFICAS}

Agamben, G. (1996). Mezzi senza fine: note sulla politica [1992]. Torino: Bollati Boringhieri.

«Notas sobre o gesto». Tradução de Vinícius Nicastro Honesko. Artefilosofia, Ouro Preto, n. ${ }^{\circ}$ 4, pp. 09-14, jan. 2008.

- (2018). Karman: court traité sur l'action, la faute et le geste. Paris: Seuil.

Benjamin, W. (2014). A obra de arte na época de sua reprodutibilidade técnica [1936]. Segunda versão. Apresentação, tradução e notas de Francisco De Ambrosis Pinheiro Machado. Porto Alegre: Zouk.

Borges Junior, E. (2018). «Os novos gestos da política: sobre cidadania e formas estéticas de resistência na era digital». Lumina, v. 12, n. ${ }^{\circ} 3$, p. 74-92. doi: https://doi.org/10.34019/19814070.2018.v12.21571.

(2020). The Theory of Algorithmic Form. Between an aesthetics and an ethics of algorithms: relations among image, enjoyment and action. 2020. Thesis (Doctorate in Communication Sciences), School of Communications and Arts, University of São Paulo, São Paulo.

Didi-Huberman, G. (2017). Levantes. Com ensaios de Nicole Brenez, Judith Butler, Marie-José Mondzain, Antonio Negri e Jacques Rancière. Trad. Edgard de Assis Carvalho, Eric R. R. Heneault, Jorge Bastos e Mariza Perassi Bosco. São Paulo: Edições Sesc.

Flusser, V. (2008). O universo das imagens técnicas: elogio da superficialidade [1985]. São Paulo: Annablume.

(2014). Gestos [1991]. Apresentação de Gustavo Bernardo. São Paulo: Annablume. 
Lipovetsky, G., Serroy, J. (2013). L'esthétisation du monde. Vivre à l'âge du capitalisme artiste. Paris: Gallimard.

SODRÉ, M. (2014). A ciência do comum: notas para o método comunicacional. Petrópolis: Vozes.

Straus, E. (2000). Du sens des sens: contribution à l'étude des fondements de la psychologie [1935]. Grenoble: Jérôme Millon. 